OPEN ACCESS

Edited by:

Nephtali Marina,

University College London,

United Kingdom

Reviewed by:

Antonio Roberto Zamunér

Catholic University of Maule, Chile

Moacir Fernandes Godoy,

Faculty of Medicine of São José do

Rio Preto, Brazil

*Correspondence:

Junbao Du

junbaodu1@126.com

Specialty section:

This article was submitted to Autonomic Neuroscience,

a section of the journa

Frontiers in Neurology

Received: 08 January 2020

Accepted: 13 May 2020

Published: 11 June 2020

Citation:

Zhang Q, Xu B and Du J (2020) Update of Individualized Treatment Strategies for Postural Orthostatic Tachycardia Syndrome in Children.

Front. Neurol. 11:525.

doi: 10.3389/fneur.2020.00525

\section{Update of Individualized Treatment Strategies for Postural Orthostatic Tachycardia Syndrome in Children}

\author{
Qingyou Zhang ${ }^{1,2}$, Bowen $X u^{1}$ and Junbao $D u^{1,3 *}$ \\ ${ }^{1}$ Department of Pediatrics, Peking University First Hospital, Beijing, China, ${ }^{2}$ Research Unit of Clinical Diagnosis and \\ Treatment of Pediatric Syncope and Cardiovascular Diseases, Chinese Academy of Medical Sciences, Beijing, China, ${ }^{3}$ Key \\ Laboratory of Molecular Cardiovascular Sciences, The Ministry of Education, Beijing, China
}

Postural orthostatic tachycardia syndrome (POTS) is a heterogeneous disease that predominantly affects children and adolescents. There is a great difference between children and adults in the diagnosis and treatment of POTS patients. POTS in children and adolescents is marked by chronic symptoms of orthostatic intolerance with a heart rate $(\mathrm{HR})$ rise of $\geq 40 \mathrm{bpm}$, or heart rate exceeding $130 \mathrm{bpm}$ for 6-12-years-old children and exceeding $125 \mathrm{bpm}$ for those 13-18 years old without orthostatic hypotension, which is different from adult patients. The three major clinical forms of POTS include hypovolemic POTS, neuropathic POTS, and hyperadrenergic POTS; these are distinguished by their major mechanisms. The different subtypes of POTS in children and adolescents each have their own clinical characteristics and biomarkers. Based on these, we propose individualized treatment strategies. Individualized management strategies based on different subtypes of POTS would largely improve the curative effects of drugs for children with POTS. However, a further clinical investigation is still required to better understand the pathophysiology and treatment options.

Keywords: autonomic dysfunction, orthostatic intolerance, postural orthostatic tachycardia syndrome, treatment, children

Postural orthostatic tachycardia syndrome (POTS) is a form of chronic orthostatic intolerance (1). POTS is more common in children than in adults, and most POTS patients develop their symptoms in childhood or adolescence $(2,3)$. It is increasingly recognized in children $(4,5)$. However, because of the varying symptoms of POTS in children and adolescents, including cardiovascular, neurologic and gastrointestinal symptoms, it is often misdiagnosed. In recent years, more and more attention has been paid to the diagnosis and treatment of this syndrome (6-9). This review details the characteristics of POTS in pediatric patients.

POTS is a syndrome, not a disease, and features hemodynamic abnormalities of upright position and other symptoms. It results in inability to attend school, take part in physical activities and even the normal activities of daily life. As a result, POTS patients face significant social and economic consequences (9-12), and early diagnosis is crucial to the launch of effective therapy. However, the clinical features of POTS in children and adolescents have not yet been fully summarized (13). Therefore, we reviewed the literature related to pediatric POTS, which provides a broad understanding of the characteristics of this syndrome. 


\section{CLINICAL CHARACTERISTIC OF POTS IN PEDIATRIC PATIENTS}

POTS is a common disorder of chronic orthostatic intolerance in children. The disorder is characterized by dizziness, palpations, fatigue, headache, chest tightness, abdominal pain, nausea, and even syncope on standing. Although its symptoms are primarily associated with the upright position, some patients report their persistence when they are sitting or lying down. The definition of POTS is that the symptoms of orthostatic intolerance persist at least 6 months, and are accompanied with an increase in heart rate (HR) exceeding $30 \mathrm{bpm}$ (or a rate that exceeds 120 $\mathrm{bpm}$ ) within 10 min of standing or achieving upright tilt without orthostatic hypotension (>20 mmHg drop in systolic blood pressure) $(1-6,8)$. However, children and adolescents display different pictures related to their particular types of growth and development. In our previous study, the HR and blood pressure of 1,449 school children (6-18 years old) in China were recorded during active standing. During tests, the HR and BP had significantly changing profiles in children and adolescents, and our group proposed that the diagnosis of POTS in the pediatric population be made when the $\mathrm{HR}$ rises by $\geq 40$ beats per minute, or the fastest heart rate of children aged 6-12 exceeded 130 beats per minute, and exceeded 125 beats per minute for adolescents aged 13-18, within $10 \mathrm{~min}$ of standing, accompanied by symptoms of orthostatic intolerance (13-15).

POTS predominantly affects females, with the ratio of females to males in adult studies being $4: 1(4,12,16)$. Researchers speculate that menstruation, which features periodic variations in levels of estrogen and progesterone, is related to the incidence of POTS (17). However, in our cohort, the male: female gender ratio was only 1:1.1, since we expected that the impact of menstruation in children would be small (5). POTS can occur throughout adolescence, and the children with POTS were mainly aged between 7 and 14 years in this study, a figure consistent with previous reports from our center $(4,5)$.

The symptoms of POTS in children and adolescents vary. Common symptoms of our patients include dizziness (84.00\%), fatigue $(72.00 \%)$, orthostatic faint $(62.67 \%)$, shortness of breath (55.33\%), pallor (51.33\%), blurred vision (50.00\%), hyperhidrosis (43.33\%), gastrointestinal difficulties (40.67\%), and fatigue (37.33\%) (5). Some authors have reported that $30 \%$ of their patients have a variety of symptoms (18). Female patients often experience a worsening of symptoms during menstruation.

The numerous co-morbidities of POTS in children have attracted the attention of many researchers. These include chronic fatigue syndrome, sleep disorders, migraines, irritable bowel syndrome or functional dyspepsia, cyclic-vomiting syndrome, fibromyalgia, and Ehlers-Danlos syndrome $(6,18)$. However, the relationship between these disorders and POTS is still unclear. Many investigators suggest that POTS share the similar mechanisms for the co-morbid disorders. However, some authors have found that no difference can be found in the incidence of those co-morbid conditions in children and adolescents with POTS and those without POTS. They are syndromes which may occur together with POTS, but POTS itself is not a cause of the co-morbidities (19).
Psychiatric disorders including anxiety and depression are associated with POTS in child and adolescent family members of patients, and child patients with POTS often encounter tragic experiences after contracting the illness, with no regular attendance at school and social activities, underachievement, and frequent visits to doctors. They often receive a variety of diagnoses, take multiple drugs, and sometimes even receive surgery.

\section{POTS SUBTYPES IN CHILDREN AND ADOLESCENTS}

Based on the mechanisms of potential pathophysiology of POTS, 3 main clinical subtypes of the syndrome have been established: hypovolemic POTS, neuropathic POTS, and hyperadrenergic POTS (20-22). These phenotypes may overlap.

\section{Hypovolemic POTS}

Central hypovolemia leads to a decrease in venous return, resulting in an increase of heart rate as compensation. Low blood volumes have been observed in many children and adolescents with POTS $(23,24)$. In patients with hypovolemia, the abnormal activation of the renin-angiotensin-aldosterone system has been found in children (24-26). Hypovolemia could be observed in nearly $30 \%$ of POTS patients, as Thieben et al. estimated (16). In our experience, over fifty percent of children and adolescents with POTS have low blood volume (5). Hypovolemic POTS patients have symptoms, such as obvious weakness and decreased tolerance for exercise. Increasing central blood volume with intravenous fluids or salt supplements can significantly improve these patients' symptoms $(23,27)$. El-Sayed and Hainsworth found that 24-h urinary sodium was a valuable marker of hypovolemic status (23). According to our research, a 24-h sodium excretion of $<124 \mathrm{mmol}$ is a good indicator of the effectiveness of replenishment of blood with salt supplementation in children and adolescents with POTS (27).

\section{Neuropathic POTS}

Partial autonomic neuropathy is the characteristics of this subtype of POTS. The main mechanism of this type of POTS is patchy denervation of the sympathetic fibers to the blood vessels in the extremities (28). We found that the incidence of Valsalva maneuver (Valsalva ratio, VR) of $<1.5$ was $84.72 \%$ in our cohort patients with POTS (5). In another study, loss of sweating function of the extremities was found in over $50 \%$ of patients with POTS (16). The denervation of the sympathetic fibers to the blood vessels in the extremities might affect their contractile function and cause the pooling of blood in the extremities. When patients stand up, their abnormal vessel tone and pooling in the lower extremities lead to a decrease of returned-blood volume, causing a decrease of cardiac output, and a heart-rate increase in compensation. We also found that some patients with POTS had augmented flow-mediated vasodilation (FMD) of the brachial artery, indicating that an increase of the vasodilation response of the peripheral may lead to the poor blood circulation of the lower extremities when standing, resulting in a decrease of returned-blood volume and symptoms of POTS (29). Severe 
venous pooling in the lower extremities is characterized by cyanosis of the feet upon standing in this subtype of POTS children. Many patients report having a history of fever before the onset of disease, likely viral infection, or having a history of surgery, infection or trauma. Therefore, some researchers propose immune pathogenesis of neuropathic POTS (30). We found that $24.39 \%$ of patients were positive for antibodies of acetylcholine receptor (AChR-ab). The symptoms of those POTS children were significantly severe and syncope and fatigue were common (31). Other autoimmune antibodies in POTS, such as alpha 1 and/or beta adrenergic-receptor autoimmune antibodies, and angiotensin II Type 1-receptor autoimmune antibodies, were also observed $(32,33)$. At present, it is considered that neuropathic POTS is a mild autoimmune disorder.

\section{Hyperadrenergic POTS}

The definition of hyperadrenergic POTS is a syndrome with an increase of above $10 \mathrm{mmHg}$ in systolic BP within $10 \mathrm{~min}$ of standing or tilting, and an upright-position plasma norepinephrin of $\geq 600 \mathrm{pg} / \mathrm{mL}$ (34, 35). In our cohort, $51.28 \%$ of children with POTS were hyperadrenergic. These patients manifested with hypertension upon standing, and may complain of lightheadedness, faintness, palpitations, shortness of breath, syncope, tremulousness, headache, fatigue and nausea and vomiting. The most common symptoms of hyperadrenergic POTS in children are dizziness, headache and tremulousness, compared with other types of POTS patients (35). Hyperadrenergic POTS can be caused by norepinephrine transporter deficiency (36), pheochromocytoma, mast-cellactivation disorders (37), and baroreflex failure resulting from trauma to or irradiation of the neck. However, most of the children had not suffered either of these.

\section{TREATMENT APPROACHES (TABLE 1)}

Accurate diagnosis is the basis for controlling this disease that excludes true cardiac disorders. The majority of patients with POTS show substantial improvement after proper diagnosis leads to a comprehensive therapeutic regimen being put in place. There are many ways to treat the disease, including drugs and physical therapy.

\section{NON-PHARMACOLOGICAL TREATMENTS}

Lowered water intake and shorter sleeping time were identified as POTS risk factors in children and adolescents (45). Health education is an important part of treatment of POTS patients. The basic treatment of the disease is to increase water and salt intake. Most children with POTS need have salt intake of up to $5-6 \mathrm{~g}$. Urine osmolality of $<300 \mathrm{mmol} / \mathrm{L}$ or 24 -h urinary sodium excretion of more than $200 \mathrm{mmol}$ are the goals (46). Good sleep may also be an important consideration, since we found that those getting $<8 \mathrm{~h}$ of sleep per day were at 5.9 times greater risk of getting POTS than those with sleeping longer than $8 \mathrm{~h}$ (45).

Some investigators have found that a regular, shortterm progressive physical-exercise program leads to improved symptoms in POTS patients (47). Such a regimen consists of rowing on a machine, swimming, recumbent and upright biking, and treadmill walking. However, one major challenge of successful physical therapy is patient compliance with regular and consistent with the program $(6,48)$.

Children and adolescents with POTS should be treated using a multidisciplinary approach that includes alternative nutritional, psychological, and drug therapies. Like other researchers, we have found that children with POTS have poor nutrition,

TABLE 1 | The main clinical studies included in the review.

\begin{tabular}{|c|c|c|c|c|c|}
\hline Study group & Methods & $\begin{array}{l}\text { No. of } \\
\text { patients }\end{array}$ & Drug & Biomarkers & Outcomes \\
\hline Lu et al. (38) & Case-control study & 35 & ORS & $\mathrm{MCHC}$ & $\mathrm{MCHC}>347.5 \mathrm{~g} / \mathrm{L}$ predicts the effect of ORS for treating POTS \\
\hline Lin et al. (40) & Case-control study & 34 & Metoprolol & CNP & $\begin{array}{l}\text { CNP }>32.55 \mathrm{pg} / \mathrm{m} \text { predicts the effect of metoprolol for treating } \\
\text { POTS }\end{array}$ \\
\hline Zhang et al. (41) & Case-control study & 27 & Metoprolol & $\begin{array}{l}\text { Orthostatic plasma } \\
\text { norepinephrine }\end{array}$ & $\begin{array}{l}\text { Orthostatic plasma norepinephrine level of }>3.59 \mathrm{pg} / \mathrm{ml} \text { predicts } \\
\text { the effect of metoprolol for treating POTS }\end{array}$ \\
\hline Yang et al. (43) & Case-control study & 28 & Midodrine & $\begin{array}{l}\text { Erythrocytic } \\
\text { hydrogen sulfide }\end{array}$ & $\begin{array}{l}\text { Erythrocytic hydrogen sulfide production rate }>27.1 \mathrm{nmol} / \mathrm{min} / 10^{8} \\
\text { erythrocytes predicts the effect of midodrine for treating POTS }\end{array}$ \\
\hline Liao et al. (29) & Case-control study & 108 & Midodrine & FMD & FMD $>9.85 \%$ predicts the effect of midodrine for treating POTS \\
\hline Zhang et al. (44) & Case-control study & 57 & Midodrine & MR-proADM & $\begin{array}{l}\text { The plasma concentration of MR-proADM }>61.5 \mathrm{pg} / \mathrm{ml} \text { predicts } \\
\text { the effect of midodrine for treating POTS }\end{array}$ \\
\hline
\end{tabular}

POTS, postural orthostatic tachycardia syndrome; ORS, oral rehydration solution; MCHC, mean corpuscular hemoglobin concentration; BMI, body mass index; CNP, C-type natriuretic peptide; FMD, flow-mediated vasodilation; MR-proADM, midregional fragment of pro-adrenomedullin. 
including low iron storage $(5,49)$, vitamin B12 deficiency (50), vitamin B1 deficiency (51), hypovitaminosis D (52), and elevated plasma homocysteine levels (53). Correcting these would be very beneficial to the recovery of patients.

\section{PHARMACOLOGICAL TREATMENTS}

There is currently no pharmacologic therapy approved by the FDA for children with POTS. All the medications used to treat POTS in children are "off-label", and most of the studies assessing POTS treatments are not evidence-based. There is lack of drug for POTS in multi-center randomized-control trials (RCT), and longitudinal long-term follow-up data of any medication for POTS are in need $(6-9,54)$. Wells et al. reported in a systemic review article that only 3 RCTs including 103 patients were studied for medications treatment of POTS in a single center (55). Our center reported that midodrine hydrochloride is effective in the treatment of children with POTS through a small non-blinded randomized controlled study (38). Drug therapy includes fludrocortisones for increasing central blood volume, the peripheral selective alpha-1-adrenergic agonist midodrine to constrict peripheral veins and reduce stagnant venous blood, $\beta$-adrenergic blockers, including non-selective propranolol, and cardioselective metoprolol, to decrease standing excessive tachycardia, and the acetylcholinesterase inhibitor pyridostigmine to increase acetylcholine on the autonomic ganglia, thereby enhancing ganglionic neurotransmission, increasing the release of norepinephrine by post-ganglionic sympathetic nerves and potentiating vagal effects upon standing $(1,4,6,8)$. However, the fact that "what works for one patient does not always work for another" was clearly displayed by this POTS patient, as Boris said (9). Wells et al. also pointed out that due to heterogeneity in the pathophysiology underlying POTS, biomarkers may play an incremental role in refining therapy (55). Based on our studies, POTS is a group of heterogeneous ailments caused by multiple sources of pathogenesis. If we could target drugs based on the pathogeneses of individual patients, the curative effects of drugs on children with POTS would be greatly enhanced. Each of the three major subtypes represents a different mechanism, and on this basis we have proposed an individualized-treatment strategy.

\section{TREATMENT OF HYPOVOLEMIC POTS: SALT SUPPLEMENTS, ORAL REHYDRATION AND FLUDROCORTISONE}

Hypovolemia can be seen in many POTS patients, and increasing fluids intake is an effective treatment of POTS symptoms. A low concentration of urinary sodium is an indirect marker of hypovolemia $(23,27)$. Our previous work showed that, compared with the healthy control group, the concentration of 24-h urinary sodium was significantly lower in the POTS patients, and the symptom severity of children with POTS inversely correlated at a significant level with their 24-h urinary-sodium concentrations. Twenty-four hours sodium concentrations of $<124 \mathrm{mmol} / 24 \mathrm{~h}$ indicated the effectiveness of salt supplements for treating POTS patients (sensitivity 76.9\%; specificity 93\%) (27).

Recent studies have found that using oral-rehydration solution (ORS) can conveniently, safely and effectively relieve the symptoms of children with POTS (56). Lu et al. found that among these children, those responding to ORS had a lower baseline mean-corpuscular volume (MCV) and higher mean-corpuscular hemoglobin concentration (MCHC) than non-responders, and that $\mathrm{MCHC}$ values are good predictors of ORS therapy for children and adolescents with POTS (39).

Stewart et al. found that, compared with POTS patients with normal blood volumes, the body-mass index (BMI) of POTS patients with hypovolemia was significantly lower. This finding suggests that BMI is related to blood volume (57). Our team found that BMI value lower than $18 \mathrm{~kg} / \mathrm{m}^{2}$ indicated the effectiveness of ORS treatment for POTS children and adolescents (sensitivity $92 \%$; specificity $82.8 \%$ ). Compared with 24 -h sodium concentrations, BMI is a simple and easily measured indicator (58).

Fludrocortisone is a synthetic mineralocorticoid that promotes the reabsorption of sodium and water in the kidneys. Therefore, it can increase plasma volume in patients with POTS (59-61). Theoretically, it can ameliorate the symptoms of hypovolemic POTS. However, compared with a placebo, fludrocortisone was found to be ineffective at relieving the symptoms of patients with neurally-mediated hypotension and chronic-fatigue syndrome in a placebocontrolled randomized trial (62). In another double-blind, placebo-controlled randomized trial, fludrocortisone also did not ameliorate the frequency of syncope in the treatment of vasovagal syncope patients (63). The reason that the drug has not been shown to be effective is non-selective use of it. Fludrocotisone should be used for hypovoleomic patients only. Also, attention should be paid to hypokalemia in the application of flurocortisoneone, since flurocortisone can promote the excretion of potassium. Fludrocortisone increases potassium excretion $(59,60)$. Fludrocortisone is now in the Heart Rhythm Society (HRS) Expert Consensus Class 2B recommendation for POTS patients (8).

\section{TREATMENT OF NEUROPATHIC POTS: MIDODRINE AND PYRIDOSTIGMINE}

In neuropathic POTS, impaired peripheral vasoconstriction caused by adrenergic denervation can lead to peripheral venous pooling (64). Midodrine, an alpha1-adrenergic agonist, can effectively constrict peripheral vessels, and increase venous return. In a small non-blinded RCT, we found that midodrine could improve the symptoms of POTS in children and reduce standing heart rate (38). In order to select the drugs accurately, we seek biomarkers that reflect the presence of peripheral vasoconstriction dysfunction in POTS patients. FMD is an ultrasound technique used to assess blood-vessel elasticity (43). We found that, compared with the control children, baseline FMD increase was significantly greater in children with POTS, and the sensitivity and specificity of FMD at $9.85 \%$ as a 
cutoff value for predicting the short-term efficacy of midodrinehydrochloride (1 month) treatment for POTS were 71.6 and $77.8 \%$, respectively (29).

Hydrogen sulfide $\left(\mathrm{H}_{2} \mathrm{~S}\right)$ is an important gaseous intracellular signal transducer. It is involved in the regulation of the cardiovascular system; it plays an important role in the pathogenesis of a variety of heart diseases, and is a novel gasotransmitter in the cardiovascular system (65). Our previous study demonstrated that erythrocytic $\mathrm{H}_{2} \mathrm{~S}$ could indicate the effectiveness of midodrine hydrochloride for treating POTS patients. The sensitivity and specificity of erythrocytic $\mathrm{H}_{2} \mathrm{~S}$ production of $27 \mathrm{nmol} / \mathrm{min} / 10^{8}$ erythrocytes as a cutoff value for predicting the effectiveness of midodrine hydrochloride for children with POTS were 78.9 and $77.8 \%$, respectively (44).

Adrenomedullin (ADM) is a potent vasodilator and has peripheral vasorelaxing effects. It is also associated with peripheral vasoconstriction and relaxation. But ADM has a short half-life, and easily adheres non-specifically to cellular surfaces, making its quantification impossible. Therefore, a midregional fragment of pro-adrenomedullin (MR-proADM), which produced quantities equivalent to those of $\mathrm{ADM}$, is more stable than ADM (42). Zhang et al. found that the responders to midodrine hydrochloride in children with POTS had higher plasma levels of MR-proADM. MR-proADM > $>61.5$ $\mathrm{pg} / \mathrm{ml}$ predicts the efficacy of midodrine-hydrochloride therapy for treating POTS (sensitivity 100\% and specificity 71.6\%) (66).

Arginine vasopressin (AVP) plays an important role in circulatory and water homoeostasis. Copeptin and arginine vasopressin (AVP) are derived from a common precursor molecule and have equimolar secretion, and copeptin is more stable in plasma than AVP. Our group found that copeptin was also a good biomarker predicting the effectiveness of midodrine hydrochloride in treating children with POTS (67). Midodrine is now in an HRS Class 2B recommendation for the treatment of POTS (8).

Neuropathic POTS is regarded as a restricted autoimmune autonomic ganglionopathy (AAG), associated with autoantibodies in the ganglionic acetylcholine receptor $(30,31)$. Along with others, we found that this type of POTS in children and adolescents was associated with positive acetylcholine receptor antibodies (AChR-ab) $(16,31)$. Pyridostigmine, a peripheral acetylcholinesterase inhibitor, could be used to treat patients with POTS. Its therapeutic mechanism involves increasing synaptic acetylcholine in the autonomic ganglia and functional enhancement of nerve conduction of parasympathetic nervous systems. It has also been shown that pyridostigmine can increase the baroreceptor sensitivity of POTS patients and thereby ameliorate their symptoms (68). In a randomized crossover study, Raj et al. found that pyridostigmine significantly attenuated tachycardia and ameliorated the symptoms of POTS, and in another long-term retrospective study they also found that pyridostigmine could improve the standing heart rate and ameliorated the symptoms of POTS $(41,68)$. Filler et al. reported that a 16-years-old girl with severe POTS was treated with pyridostigmine, and that after 9 months there were persistent positive effects without additional blood-pressure abnormalities (40). We propose that if a child with POTS is seropositive for AChR-ab, pyridostigmine should be used appropriately. It is in an HRS Class $2 \mathrm{~B}$ recommendation for the treatment of POTS (8).

\section{TREATMENT OF HYPERADRENERGIC POTS: $\beta$-BLOCKERS}

The characteristics of hyperadrenergic POTS is an elevated upright plasma norepinephrine levels. This subtype of patients with orthostatic hypertension has posed a great challenge to the traditional treatment of POTS $(34,35)$. Salt supplements and peripheral vasoconstrictor-midodrine should be used with caution in treating these patients. In the treatment of this type of POTS, $\beta$-blockers for blocking $\beta$-adrenoceptors are preferred, which could prevent the effect of having excessive catecholamines in the plasma. We found that the severity of symptoms and increments of the heart rate when standing was positively correlated with the plasma norepinephrine levels of patients in upright positions, and compared with non-responders to metoprolol, the upright plasma norepinephrine levels in responders to metoprolol were significantly high. The sensitivity and specificity of an orthostatic plasma-norepinephrine level of $3.59 \mathrm{mmol} / \mathrm{ml}$ as a cutoff value for predicting the effectiveness of metoprolol for children with POTS were 76.9 and $91.7 \%$, respectively (69). However, plasma-norepinephrine levels were not stable in circulation, and were affected by many factors, including exercise and emotions. Thus, we should seek a stable, easily detected and inexpensive biomarker of hyperadrenergic POTS. C-type natriuretic peptide (CNP) is a regulatory peptide that can affect catecholamine release. Lin et al. reported that, compared with non-responders to metoprolol therapy of POTS in children and adolescents, plasma CNP in responders was significantly high before treatment, and baseline plasma CNP of $>32.6 \mathrm{pg} / \mathrm{ml}$ predicted the efficacy of metoprolol therapy for treating POTS in children (sensitivity $100 \%$ and specificity 71.6\%). Thus, plasma CNP is a useful clinical predictor of the therapeutic response to metoprolol in POTS patients (70).

Propranolol, a non-selective $\beta$-blocker, can pass the bloodbrain barrier. Thus, it is considered to work better than other $\beta$-blockers in the treatment of POTS (71). Some studies have found that low doses of propranolol are superior to higher doses in the treatment of POTS adult patients. Low dosages of oral propranolol ameliorates the upright tachycardia and enhances the capacity for exercise of POTS patients (72). Propranolol is also used as a migraine prophylaxis medication (73), making it sometimes useful for treating patients with POTS co-morbid migraine. Propranolol is in an HRS Class 2B recommendation for treatment of POTS (8).

In summary, we have categorized the pathophysiology of POTS into 3 major subtypes that may overlap: hypovolemic, neuropathic and hyperadrenergic. It is important to note that strategies that work for some patients may not be applicable to all. Thus, in clinical practice, it is very important to search for biomarkers of the pathogenesis of POTS in children as a guide to select the drugs best suited to any given individuals. With this goal in mind, we have proposed 


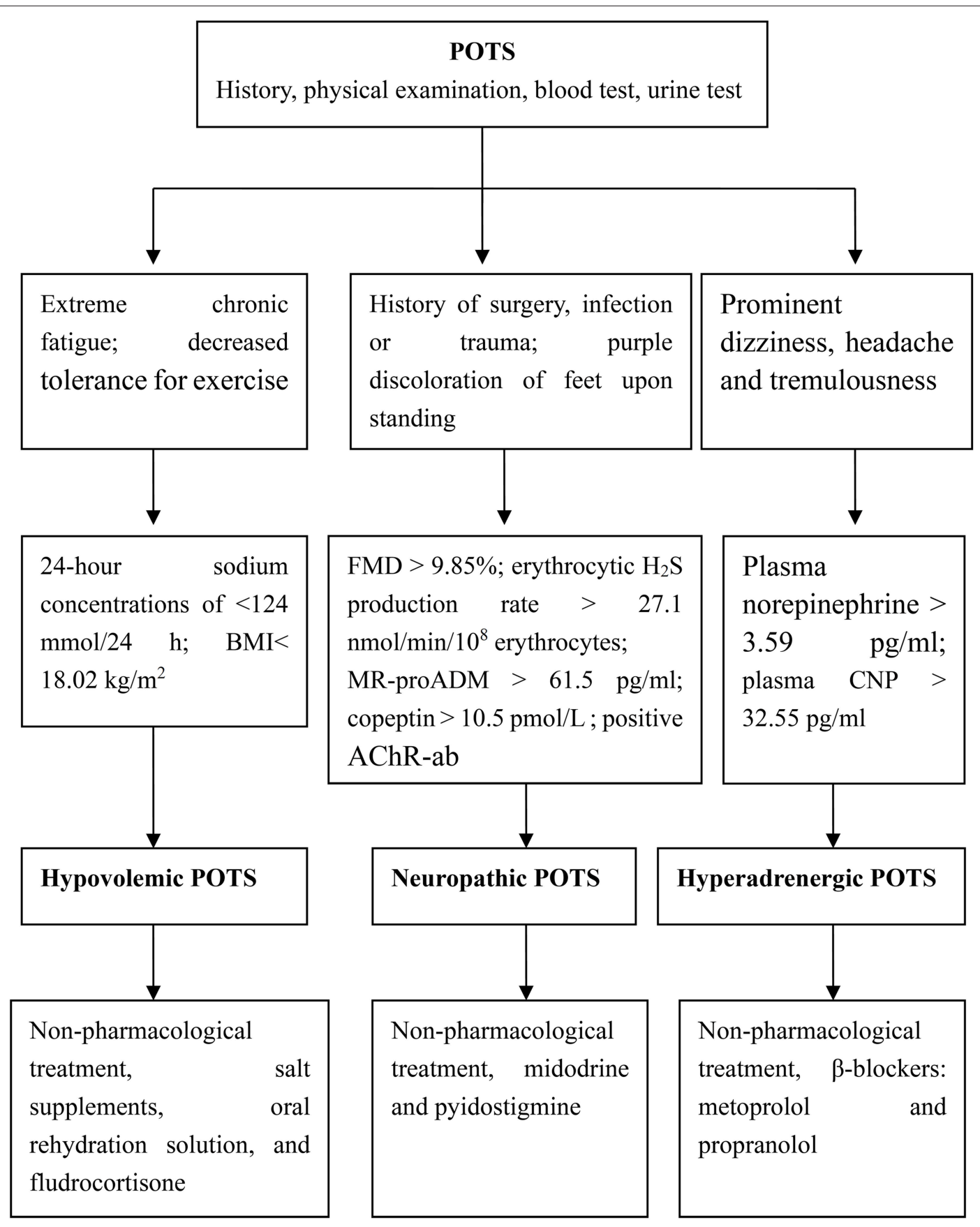

FIGURE 1 | Individualized treatment strategies for children based on POT subtypes. POTS, postural orthostatic tachycardia syndrome; BMI, body-mass index; FMD, flow-mediated vasodilation; MR-proADM, mid-regional fragment of pro-adrenomedullin; AChR-ab, antibodies of acetylcholine receptor; CNP, C-type natriuretic peptide.

a subtype pathophysiology-based personalized-treatment strategy (Figure 1).

\section{CONCLUSION}

POTS is a common and heterogeneous disorder in children and adolescents that significantly reduces quality of life. Its common categories are hypovolemic, hyperadrenergic and neuropathic. Management always involves cross-disciplinary care that includes lifestyle changes, nutritional adjustments, exercise and drugs. Different sub-types of POTS have different clinical characteristics, and involve different physiological and biochemical changes. Some biomarkers reflect the pathogenesis of POTS in children and guide the choice of 
drugs for individualized treatment. However, a further clinical investigation of its pathophysiology and the options for treating it is still required.

\section{AUTHOR CONTRIBUTIONS}

QZ had primary responsibility for the design and execution of the study, data collection, preliminary data analysis, and writing the manuscript. BX participated in data collection, preliminary data analysis, and the writing of the manuscript. JD supervised

\section{REFERENCES}

1. Stewart JM. Orthostatic intolerance in pediatrics. J Pediatr. (2002) 140:40411. doi: $10.1067 / \mathrm{mpd} .2002 .122727$

2. Tanaka H, Fujita Y, Takenaka Y, Kajiwara S, Masutani S, Ishizaki Y, et al. Japanese clinical guidelines for juvenile orthostatic dysregulation version 1. Pediatr Int. (2009) 51:169-79. doi: 10.1111/j.1442-200X.2008.02783.x

3. Zhang Q, Du J, Wang C, Du Z, Wang L, Tang C. The diagnostic protocol in children and adolescents with syncope-a multi-center prospective study. Acta Pediatr. (2009) 98:879-84. doi: 10.1111/j.1651-2227.2008.01195.x

4. Medow MS. Postural tachycardia syndrome from a pediatrics perspective. $J$ Pediatr. (2011) 158:4-6. doi: 10.1016/j.jpeds.2010.08.038

5. Li J, Zhang Q, Hao H, Jin H, Du J. Clinical features and management of postural tachycardia syndrome in children: a single-center experience. Chin Med J (Engl). (2014) 127:3684-9. doi: 10.3760/cma.j.issn.0366-6999.20140244

6. Bryarly M, Phillips LT, Fu Q, Vernino S, Levine BD. Postural Orthostatic Tachycardia syndrome: JACC focus seminar. J Am Coll Cardiol. (2019) 73:1207-28. doi: 10.1016/j.jacc.2018.11.059

7. Wang C, Li Y, Liao Y, et al. Chinese Pediatric Cardiology Society (CPCS) guideline for diagnosis and treatment of syncope in children and adolescents. Sci Bull. (2018) 63:1558-64. doi: 10.1016/j.scib.2018.09.019

8. Sheldon RS, Grubb BP II, Olshansky B, Shen WK, Calkins H, Brignole M, et al. 2015 Heart Rhythm Society expert consensus statement on the diagnosis and treatment of postural tachycardia syndrome, inappropriate sinus tachycardia, and vasovagal syncope. Heart Rhythm. (2015) 12:e4163. doi: 10.1016/j.hrthm.2015.03.029

9. Boris JR. Postural orthostatic tachycardia syndrome in children and adolescents. Auton Neurosci. (2018) 215:97101. doi: 10.1016/j.autneu.2018.05.004

10. Kizilbash SJ, Ahrens SP, Bruce BK, Chelimsky G, Driscoll SW, HarbeckWeber C, et al. Adolescent fatigue, POTS, and recovery: a guide for clinicians. Curr Probl Pediatr Adolesc Health Care. (2014) 44:10833. doi: 10.1016/j.cppeds.2013.12.014

11. Bruce BK, Harrison TE, Bee SM, Luedtke CA, Porter CJ, Fischer $\mathrm{PR}$, et al. Improvement in functioning and psychological distress in adolescents with postural orthostatic tachycardia syndrome following interdisciplinary treatment. Clin Pediatr (Phila). (2016) 55:1300-4. doi: 10.1177/0009922816638663

12. Shaw BH, Stiles LE, Bourne K, Green EA, Shibao CA, Okamoto LE, et al. The face of postural tachycardia syndrome-insights from a large crosssectional online community-based suvery. J Intern Med. (2019) 286:43848. doi: 10.1111/joim.12895

13. Stewart JM. A new guideline for diagnosis and treatment of syncope in children and adolescents that stimulates further thought and discussion. Sci Bull. (2018) 63:1527-8. doi: 10.1016/j.scib.2018.09.020

14. Zhao J, Han Z, Zhang X, Du S, Liu AD, Holmberg L, et al. A cross-sectional study on upright heart rate and BP changing characteristics: basic data for establishing diagnosis of postural orthostatic tachycardia syndrome and orthostatic hypertension. BMJ Open. (2015) 5:e007356. doi: 10.1136/bmjopen-2014-007356

15. Tao C, Liu X, Zhang C, Chen Y. Comments on 2018 CPCS guideline for diagnosis and treatment of syncope in children and adolescents. Sci Bull. (2019) 64:291-2. doi: 10.1016/j.scib.2019.01.008 the design and execution of the study, performed the final data analyses, and contributed to the writing of the manuscript.

\section{FUNDING}

This work was supported by National Natural Science Foundation of China (81921001), CAMS Innovation Fund for Medical Sciences (2019-I2M-5-047), Peking University Clinical Scientist Program (BJMU2019LCKXJ001), and the Fundamental Research Funds for the Central Universities.
16. Thieben MJ, Sandroni P, Sletten DM, Benrud-Larson LM, Fealey RD, Vernino $\mathrm{S}$, et al. Postural orthostatic tachycardia syndrome: the mayo clinic experience. Mayo Clin Proc. (2007) 82:308-13. doi: 10.4065/82.3.308

17. Fu Q, VanGundy TB, Shibata S, Auchus RJ, Williams GH, Levine BD. Menstrual cycle affects renal-adrenal and hemodynamic responses during prolonged standing in the postural orthostatic tachycardia syndrome. Hypertension. (2010) 56:82-90. doi: 10.1161/HYPERTENSIONAHA.110.151787

18. Boris JR, Bernadzikowski T. Demographics of a large paediatric postural orthostatic tachycardia syndrome program. Cardiol Young. (2018) 28:66874. doi: 10.1017/S1047951117002888

19. Chelimsky G, Kovacic K, Nugent M, Mueller A, Simpson P, Chelimsky TC. Comorbid conditions do not differ in children and young adults with functional disorders with or without postural tachycardia syndrome. J Pediatr. (2015) 167:120-4. doi: 10.1016/j.jpeds.2015.03.039

20. Jarjour IT. Postural tachycardia syndrome in children and adolescents. Semin Pediatr Neurol. (2013) 20:18-26. doi: 10.1016/j.spen.2013.01.001

21. Benarroch EE. Postural tachycardia syndrome: a heterogeneous and multifactorial disorder. Mayo Clin Proc. (2012)87:121425. doi: 10.1016/j.mayocp.2012.08.013

22. Mar PL, Raj SR. Postural orthostatic tachycardia syndrome: mechanisms and new therapies. Annu Rev Med. (2019) 7:23548. doi: 10.1146/annurev-med-041818-011630

23. El-Sayed H, Hainsworth R. Salt supplement increases plasma volume and orthostatic tolerance in patients with unexplained syncope. Heart. (1996) 75:134-40. doi: 10.1136/hrt.75.2.134

24. Li J, Liao Y, Du J, Zhang Q. Relationship between 24-hour urinary sodium and renin-angiotensin-aldosterone system in children with postural tachycardia syndrome. Zhonghua Yi Xue Za Zhi. (2015) 95:2928-32. doi: 10.3760/cma.j.issn.0376-2491.2015.36.009

25. Raj SR, Biaggioni I, Yamhure PC, Black BK, Paranjape SY, Byrne DW, et al. Renin-aldosterone paradox and perturbed blood volume regulation underlying postural tachycardia syndrome. Circulation. (2005) 111:157482. doi: 10.1161/01.CIR.0000160356.97313.5D

26. Mustafa HI, Garland EM, Biaggioni I, Black BK, Dupont WD, Robertson $\mathrm{D}$, et al. Abnormalities of angiotensin regulation in postural tachycardia syndrome. Heart Rhythm. (2011) 8:422-8. doi: 10.1016/j.hrthm.2010.11.009

27. Zhang Q, Liao Y, Tang C, Du J, Jin H. Twenty-four-hour urinary sodium excretion and postural orthostatic tachycardia syndrome. J Pediatr. (2012) 161:281-4. doi: 10.1016/j.jpeds.2012.01.054

28. Gibbons $\mathrm{CH}$, Bonyhay I, Benson A, Wang N, Freeman R.Structural and functional small fiber abnormalities in the neuropathic postural tachycardia syndrome. PLoS ONE. (2013) 8:e84716. doi: 10.1371/journal.pone.0084716

29. Liao Y, Yang J, Zhang F, Chen S, Liu X, Zhang Q, et al. Flowmediated vasodilation as a predictor of therapeutic response to midodrine hydrochloride in children with postural orthostatic tachycardia syndrome. Am J Cardiol. (2013) 112:816-20. doi: 10.1016/j.amjcard.2013.05.008

30. Steven V, Lauren ES. Autoimmunity in postural orthostatic tachycardia syndrome: current understanding. Auton Neurosci. (2018) 215:78-82. doi: 10.1016/j.autneu.2018.04.005

31. Li J, Zhang Q, Liao Y, Zhang C, Hao H, Du J. The value of acetylcholine receptor antibody in children with postural tachycardia syndrome. Pediatr Cardiol. (2015) 36:165-70. doi: 10.1007/s00246-014-0981-8 
32. Fedorowski A, Li H, Yu X, Koelsch KA, Harris VM, Liles C, et al. Antiadrenergic autoimmunity in postural tachycardia syndrome. Europace. (2017) 19:1211-9. doi: 10.1093/europace/euw154

33. Yu X, Li H, Murphy TA, Nuss Z, Liles C, Aston CE, et al. Angiotensin II Type 1 receptor autoantibodies in postural tachycardia syndrome. J Am Heart Assoc. (2018) 7:e008351. doi: 10.1161/JAHA.117.008351

34. Kanjwal K, Saeed B, Karabin B, Kanjwal Y, Grubb BP. Clinical presentation andmanagement of patients with hyperadrenergic postural orthostatic tachycardia syndrome. A single center experience. Cardiol J. (2011) 18:52731. doi: $10.5603 /$ CJ.2011.0008

35. Zhang Q, Chen X, Li J, Du J. Clinical features of hyperadrenergic postural tachycardia syndrome in children. Pediatr Int. (2014) 56:8136. doi: $10.1111 /$ ped.12392

36. Shannon JR, Flattem NL, Jordan J, Jacob G, Black BK, Biaggioni I, et al. Orthostatic intolerance and tachycardia associated with norepinephrine-transporter deficiency. $N$ Engl J Med. (2000) 342:541-9. doi: 10.1056/NEJM200002243420803

37. Shibao C, Arzubiaga C, Roberts LJ II, Raj S, Black B, Harris $\mathrm{P}$, et al. Hyperadrenergic postural tachycardia syndrome in mast cell activation disorders. Hypertension. (2005) 45:38590. doi: 10.1161/01.HYP.0000158259.68614.40

38. Chen L, Wang L, Sun J, Qin J, Tang C, Jin H, et al. Midodrine hydrochloride is effective in the treatment of children with postural orthostatic tachycardia syndrome. Circ J. (2011) 75:927-31. doi: 10.1253/circj.CJ-10-0514

39. Lu W, Yan H, Wu S, Xu W, Jin H, Du J. Hemocytometric Measures predict the efficacy of oral rehydration for children with postural tachycardia syndrome. J Pediatr. (2017) 187:220-4. doi: 10.1016/j.jpeds.2017.04.034

40. Filler G, Gow RM, Nadarajah R, Jacob P, Johnson G, Zhang YL, et al. Pharmacokinetics of pyridostigmine in a child with postural tachycardia syndrome. Pediatrics. (2006) 118:e1563-8. doi: 10.1542/peds.2006-0904

41. Kanjwal K, Karabin B, Sheikh M, Elmer L, Kanjwal Y, Saeed B, et al. Pyridostigmine in the treatment of postural orthostatic tachycardia: a single-center experience. Pacing Clin Electrophysiol. (2011) 34:7505. doi: 10.1111/j.1540-8159.2011.03047.x

42. Al-omari MA, Khaleghi M, Mosley TH Jr, Morgenthaler NG, Struck J, Bergmann A, et al. Mid-regional pro-adrenomedullin is associated with pulse pressure, left ventricular mass, and albuminuria in African Americans with hypertension. Am J Hypertens. (2009) 22:860-6. doi: 10.1038/ajh.2009.82

43. Liao Y, Chen S, Liu X, Zhang Q, Ai Y, Wang Y, et al. Flowmediated vasodilation and endothelium function in children with postural orthostatic tachycardia syndrome. Am J Cardiol. (2010) 106:378-82. doi: 10.1016/j.amjcard.2010.03.034

44. Yang J, Zhao J, Du S, Liu D, Fu C, Li X, et al. Postural orthostatic tachycardia syndrome with increased erythrocytic hydrogen sulfide and response to midodrine hydrochloride. J Pediatr. (2013) 163:1169-73. doi: 10.1016/j.jpeds.2013.04.039

45. Lin J, Han Z, Li X, Ochs T, Zhao J, Zhang X, et al. Risk factors for postural tachycardia syndrome in children and adolescents. PLOS ONE. (2014) 9:e113625. doi: 10.1371/journal.pone.0113625

46. Stewart JM, Boris JR, Chelimsky G, Fischer PR, Fortunato JE, Grubb BP, et al. Pediatric disorders of orthostatic intolerance. Pediatrics. (2018) 141:e20171673. doi: 10.1542/peds.2017-1673

47. George SA, Bivens TB, Howden EJ, Saleem Y, Galbreath MM, Hendrickson D, et al. The International POTS Registry: evaluating the efficacy of an exercise training intervention in a community setting. Heart Rhythm. (2016)13:94350. doi: 10.1016/j.hrthm.2015.12.012

48. Sousa A, Lebreiro A, Freitas J, Maciel MJ. Long-term follow-up of patients with postural tachycardia syndrome. Clin Auton Res. (2012) 22:1513. doi: 10.1007/s10286-011-0155-1

49. Jarjour IT, Jarjour LK. Low iron storage and mild anemia in postural tachycardia syndrome in adolescents. Clin Auton Res. (2013) 23:1759. doi: 10.1007/s10286-013-0198-6

50. Öner T, Guven B, Tavli V, Mese T, Yilmazer MM, Demirpence S. Postural orthostatic tachycardia syndrome (POTS) and vitamin B12 deficiency in adolescents. Pediatrics. (2014) 133:e138-42. doi: 10.1542/peds.2012-3427

51. Blitshteyn S. Vitamin B1 deficiency in patients with postural tachycardia syndrome (POTS). Neurol Res. (2017) 39:6858. doi: $10.1080 / 01616412.2017 .1331895$
52. Antiel RM, Caudill JS, Burkhardt BE, Brands CK, Fischer PR Iron insufficiency and hypovitaminosis $\mathrm{D}$ in adolescents with chronic fatigue and orthostatic intolerance. South Med J. (2011) 104:609-11. doi: 10.1097/SMJ.0b013e3182246809

53. Li Y, He B, Li H, Zhang Q, Tang C, Du J, Jin H. Plasma homocysteine level in children with postural tachycardia syndrome. Front Pediatr. (2018) 6:375. doi: 10.3389/fped.2018.00375

54. Xu WR, Wang TY. Diagnosis and treatment of syncope in pediatric patients: a new guideline. Sci Bull. (2019) 64:357. doi: 10.1016/j.scib.2019.01.024

55. Wells R, Elliott AD, Mahajan R, Page A, Lodice V, Sanders P, et al. Efficacy of therapies for postural tachycardia syndrome: a systematic review and meta-analysis. Mayo Clin Proc. (2018)93:104353. doi: 10.1016/j.mayocp.2018.01.025

56. Medow MS, Guber K, Chokshi S, Terilli C, Visintainer P, Stewart JM. The benefits of oral rehydration on orthostatic intolerance in children with postural tachycardia syndrome. J Pediatr. (2019) 214:96102. doi: 10.1016/j.jpeds.2019.07.041

57. Stewart JM, Taneja I, Medow MS. Reduced body mass index is associated with increased angiotensin II in young women with postural tachycardia syndrome. Clin Sci (Lond). (2007) 113:449-57. doi: 10.1042/CS200 70104

58. Li H, Wang Y, Liu P, Chen Y, Feng X, Tang C, et al. Body mass index (BMI) is associated with the therapeutic response to oral rehydration solution in children with postural tachycardia syndrome. Pediatr Cardiol. (2016) 37:1313-8. doi: 10.1007/s00246-016-1436-1

59. Miller AJ, Raj SR. Pharmacotherapy for postural tachycardia syndrome. Auton Neurosci. (2018) 215:28-36. doi: 10.1016/j.autneu.2018.04.008

60. Zadourian A, Doherty TA, Swiatkiewicz I, Taub PR. Postural orthostatic tachycardia syndrome: prevalence, pathophysiology, and management. Drugs. (2018) 78:983-94. doi: 10.1007/s40265-018-0931-5

61. Freitas J, Santos R, Azevedo E, Costa O, Carvalho M, de Freitas AF. Clinical improvement in patients with orthostatic intolerance after treatment with bisoprolol and fludrocortisone. Clin Auton Res. (2000) 10:2939. doi: 10.1007/BF02281112

62. Rowe PC, Calkins H, DeBusk K, McKenzie R, Anand R, Sharma G, et al. Fludrocortisone acetate to treat neurally mediated hypotension in chronic fatigue syndrome: a randomized controlled trial. JAMA. (2001) 285:529. doi: 10.1001/jama.285.1.52

63. Sheldon R, Raj SR, Rose MS, Morillo CA, Krahn AD, Medina E, et al. Fludrocortisone for the prevention of vasovagal syncope: a randomized, placebo-controlled trial. J Am Coll Cardiol. (2016) 68:1-9. doi: 10.1016/j.jacc.2016.04.030

64. Streeten DH. Pathogenesis of hyperadrenergic orthostatic hypotension. Evidence of disordered veous innervation exclusively in the lower limbs. J Clin Invest. (1990) 86:1582-8. doi: 10.1172/JCI114878

65. Tang C, Li X, Du J. Hydrogen sulfide as a new endogenous gaseous transmitter in the cardiovascular system. Curr Vasc Pharmacol. (2006) 4:1722. doi: 10.2174/157016106775203144

66. Zhang F, Li X, Ochs T, Chen L, Liao Y, Tang C, et al. Midregional pro-adrenomedullin as a predictor for therapeutic response to midodrine hydrochloride in children with postural orthostatic tachycardia syndrome. $J$ Am Coll Cardiol. (2012) 60:315-20. doi: 10.1016/j.jacc.2012.04.025

67. Zhao J, Tang C, Jin H, Du J. Plasma copeptin and therapeutic effectiveness of midodrine hydrochloride on postural tachycardia syndrome in children. $J$ Pediatr. (2014) 165:290-4. doi: 10.1016/j.jpeds.2014.04.032

68. Raj SR, Black BK, Biaggioni I, Harris PA, Robertson D. Acetylcholinesterase inhibition improves tachycardia in postural tachycardia syndrome. Circulation. (2005) 111:273440. doi: 10.1161/CIRCULATIONAHA.104.497594

69. Zhang Q, Chen X, Li J, Du J. Orthostatic plasma norepinephrine level as a predictor for therapeutic response to metoprolol in children with postural tachycardia syndrome. J Transl Med. (2014) 12:249. doi: 10.1186/s12967-014-0249-3

70. Lin J, Han Z, Li H, Chen SY, Li X, Liu P, et al. Plasma Ctype natriuretic peptide as a predictor for therapeutic response to metoprolol in children with postural tachycardia syndrome. PLoS ONE. (2015) 10:e121913. doi: 10.1371/journal.pone.01 21913 
71. Low PA, Sandroni P, Joyner M, Shen WK. Postural tachycardia syndrome (POTS). J Cardiovasc Electrophysiol. (2009) 20:3528. doi: 10.1111/j.1540-8167.2008.01407.x

72. Raj SR, Black BK, Biaggioni I, Paranjape SY, Ramirez M, Dupont WD, et al. Propranolol decreases tachycardia and improves symptoms in the postural tachycardia syndrome: less is more. Circulation. (2009) 120:72534. doi: 10.1161/CIRCULATIONAHA.108.846501

73. Pringsheim T, Davenport W, Mackie G, Worthington I, Aubé M, Christie SN, et al. Canadian Headache Society guideline for migraine prophylaxis: supplement 2. Can J Neurol Sci. (2012) 39:S1-59. doi: $10.1017 /$ S0317167100015109
Conflict of Interest: The authors declare that the research was conducted in the absence of any commercial or financial relationships that could be construed as a potential conflict of interest.

Copyright (๑) 2020 Zhang, Xu and Du. This is an open-access article distributed under the terms of the Creative Commons Attribution License (CC BY). The use, distribution or reproduction in other forums is permitted, provided the original author(s) and the copyright owner(s) are credited and that the original publication in this journal is cited, in accordance with accepted academic practice. No use, distribution or reproduction is permitted which does not comply with these terms. 